NASA Technical Memorandum 107467

AIAA-97-0150

\title{
Collective Interaction of a Compressible Periodic Parallel Jet Flow
}

Jeffrey Hilton Miles

Lewis Research Center

Cleveland, Ohio

Prepared for the

35th Aerospace Sciences Meeting and Exhibit

sponsored by the American Institute of Aeronautics and Astronautics

Reno, Nevada, January 6-10, 1997

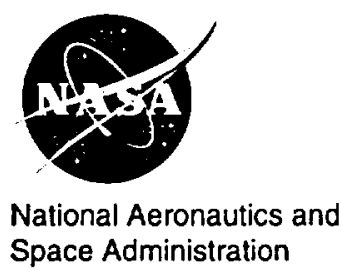





\title{
Collective Interaction of a Compressible Periodic Parallel Jet Flow
}

\author{
Jeffrey Hilton Miles* \\ National Aeronautics and Space Administration \\ Lewis Research Center \\ Cleveland, OII 44135
}

\begin{abstract}
A linear instability model for multiple spatially periodic supersonic rectangular jets is solved using FloquetBloch theory. The disturbance environment is investigated using a two dimensional perturbation of a mean flow. For all cases large temporal growth rates are found. This work is motivated by an increase in mixing found in experimental measurements of spatially periodic supersonic rectangular jets with phase-locked screech. The results obtained in this paper suggests that phase-locked screech or edge tones may produce correlated spatially periodic jet flow downstream of the nozzles which creates a large span wise multi-nozzle region where a disturbance can propagate. The large temporal growth rates for eddies obtained by model calculation herein are related to the increased mixing since eddies are the primary mechanism that transfer energy from the mean flow to the large turbulent structures. Calculations of growth rates are presented for a range of Mach numbers and nozzle spacings corresponding to experimental test conditions where screech synchronized phase locking was observed. The model may be of significant scientific and engineering value in the quest to understand and construct supersonic mixer-ejector nozzles which provide increased mixing and reduced noise.
\end{abstract}

\section{Introduction}

Interest in proving the economic and environmental feasibility of a high-speed civil transport has stimulated studies of mixing enhancement in lobed mixer-ejector nozzles. By enhancing mixing the ejector length can be reduced with the same amount of noise suppression. In order to obtain information on such flows simpler configurations are studied. In particular, a simple mixer nozzle

\footnotetext{
*Aerospace Engineer, Member AIAA
}

configuration consisting of multiple rectangular nozzles with a synchronized screech instability was studied by Taghavi and Raman ${ }^{1}$ and Raman and Taghavi ${ }^{2,3}$. This nozzle showed increased mixing with the jets synchronized. The same behavior is shown in a study of the effect of edge tones on multiple jet mixing of high-speed flows by Krothapalli et. al. ${ }^{4}$ using the nozzle described by krothapalli et. al. ${ }^{\mathbf{5}}$.

A study of an array of subsonic jets imbedded in a square network by Villermaux and IIopfinger ${ }^{6}$ and Villermaux. Gagne, and Hopfinger ${ }^{7}$ found the existence of propagating waves along the lattice. In addition, it was found that two jets separated by a distance up to five meshes had correlated oscillations.

In this paper, the temporal dynamics produced by the collective interaction of jets is discussed. It is proposed that at some point before the jets merge it is possible to investigate the flow dynamics using a model based on a two dimensional perturbation of a mean flow. This paper shows a large-scale propagation of instabilities with high growith rates may occur.

For single nozzles a reduction in mixing and growth rates with increasing Mach number has been demonstrated experimentally by many investigators ${ }^{8-12}$. Corresponding linear stability analysis of single nozzles shows results that are similar to the experimental studies ${ }^{13-15}$. This is attributed to the fact that eddies are the primary mechanism that transfer energy from the mean flow to the large lurbulent structures. However, the following study is based on the idea that these experimental and theoretical results do not apply to the mixing of multiple supersonic rectangular jets with phase locked screech. This paper is based on a linear stability analysis of compressible periodic parallel jet flows which was undertaken to obtain results related to lobed mixer nozzles. In this study, the lobed nozzle design concept is extrapolated in a one dimensional manner to arrive at an array of parallel rectangular nozzles separated by a distance $s$ where the smaller dimension of each nozzle is $w_{N}$ and the longer dimension $b$ is taken to be infinite. Note that it is assumed that even widely spaced rectangular jets which are phaselocked by screech are coherent spatially at some distance from the nozzle. Consequently, in this linear stability analysis of pertubations about the mean now, it is the colleclive behavior of compressible periodic parallel jet flow that determines the nozzle interaction.

For each operating condition, the unstable wave is as- 
sumed to grow at the maximum rate possible. In this paper, the behavior of the maximum growth rate solutions is discussed and only the trace of solutions for the group that produced the maximum growth rate for each case studied is presented.

\section{Results}

The nozzle configuration is shown in Figure 1. In this paper, the flow is compressible and the velocity profile perpendicular to the flow is adapted from an equation used by Monkewitz ${ }^{16}$ in a study of the absolute and convective instability of two-dimensional wakes. A discussion of the problem formulation is given in Appendix A. A typical velocity profile is shown in Figure 2.

The linear stability analysis is done using FloquetBloch theory. It is assumed that in the region of interest a coherent wave can propagate and that this wave can be described in terms of a mean flow perturbation. This type of analysis has been applied by Beaumont ${ }^{17}$ to an incompressible flow with a sinusoidal velocity profile perpendicular to the flow. This analysis procedure is discussed in Appendix B

Stability information is obtained using the flow model described in Appendix $A$ and the Floquet-Bloch method described in Appendix $B$. The flow disturbance is characterized by a real wave number, $\hat{k}$, and a complex relative phase velocity, $\hat{c}=\hat{c}_{r}+\imath \hat{c}_{i}$. For a given value of jet Mach number, $M_{j}$, ratio of inter jet spacing to rectangular nozzle smallest dimension $\left(s / w_{N}\right)$, and $\hat{c}_{i}$, a range of $\hat{k}$ values are studied to determine if a growing disturbance characterized by a periodicity paramater $\Gamma_{i}$ and a convective phase velocity $\hat{c}_{r}$ exists. The computer program evaluates solutions at one hundred fixed values of $\hat{c}_{r}$ in the range $-1<\hat{c}_{r}<1$. A solutions at a given value $\hat{c}_{r}$ is accepted if the calculated value of $\Gamma_{r}$ is smaller than 1.E -06 and the calculated value of $\delta$ is less than 2 ( $\delta$ is defined in Appendix B). All solutions are tabulated and a further search is made in the $\hat{c}_{r}$ region where $\Gamma_{r}$ is smallest to find the desired result. The reported results at each value of $\hat{k}$ are limited to three: no solution, one solution or two solutions. It is possible that more than two solutions exist. The model was developed to study wave growth, $\hat{\omega}_{i}=0.5 \hat{k} \hat{c}_{i}$ over a range of Mach numbers and flow geometries for compressible periodic parallel jet flow when the flow is correlated between the jets.

The Mach number and spacing for the conditions studied correspond to cases where phase locking was achieved using synchronized screech by Taghavi and $\operatorname{Raman}^{1}$ and Raman and Taghavi ${ }^{2,3}$.

For each condition studied, solutions for a range of $\hat{k}$ values at a given value of $\hat{c}_{i}$ were produced to find the region where the growth rate maximum, $\omega_{i}=0.5 \hat{k}_{\hat{c}_{i}}$, of the unstable wave occurred. The value of $\hat{c}_{i}$ used were between 0 . and 1. using steps of 0.1 . The value of $\hat{k}$ used started at 0 and increased by 0.005 . In general, blocks of $50 \hat{k}$ points were examined at a one time and the calculation for a particular value of $\hat{c}_{i}$ was abandoned if the current block of 50 points and the previous block of 50 points had no solutions.

To provide some information on the solution space, the trace of $\hat{c}_{r}$ and $\Gamma_{i}$ for the group of solutions at the value of $\hat{c}_{i}$ that produced the maximum growth rate for each case studied is presented. Figures 3 through 17 show typical stability plots of phase speed $\hat{c}_{r}$, and $\Gamma_{i}$ as a function of wave growth, $\hat{\omega}_{i}=0.5 \hat{k} \hat{c}_{i}$.

The following features of these plots are noteworthy. Examination of the plots shows that at low Mach numbers the solutions are double valued at the lower growth rates (Figs. 3, 4, 15 and 16). The trace of the plots of $\dot{c}_{r}$ and $\Gamma_{i}$ have breaks where no solution was found (Figs. $3,4,8,13$ and 15). The same Mach number (1.4) was used to calculate the results shown in Figure $6\left(\frac{\dot{\omega}}{\omega_{N}}=5.16\right.$ ) and Figure $17\left(\frac{s}{w N}=5\right)$. The slight difference in spacing produces small differences in the plots of $\hat{c}_{r}$ and $\Gamma_{i}$ indicating that the calculations are internally consistent.

However, the most important feature is that for the solution with the maximum growth rate the value of $\Gamma_{i}$ tends to be zero. This means that the periodicity of the fastest growing instability wave is the same as the periodicity of the nozzle geometry. Consequently, it is possible to achieve large growth rates without an infinite array of nozzles. This analysis indicates an array of four or five nozzles should behave like an array of forty or fifty nozzles.

The stability model is not related to screech. IIowever, it does depend on the presence of a large span wise multinozzle region where a coherent wave can propagate. In this paper, it is suggested that this region can be created by phase locked screech or edge-tones.

For each case, the solution values at $\left(\omega_{i}\right)_{\max }$ are given in Table I which shows the fully expanded Mach number, $M_{j}$, the flow profile parameter, $\Lambda$, and the ratio of the ratio of nozzle spacing, $s$, to narrow width of rectangular nozzle, $w_{N}$, the real and imaginary values of the phase speed $\hat{c}$, the parameter $\Gamma_{i}$, the wave number $\hat{k}$, the growth rate, $(\hat{\omega})_{\max }$, and the scale factor $L *$. The nozzle width, $w_{N}$, is $0.0069 \mathrm{~m}$.

The growth rates are large. In addition, examination of table $I$ indicates a tendency for the value of $\hat{c}_{i}$ to decrease with Mach number. However, the corresponding value of $k$ tends to increase with Mach number. Consequently, the maximum value of the growth rate, $\left(\hat{\omega}_{i}\right)_{\text {max }}$, does not decrease drastically with Mach number. These large growth rates of spatially coherent waves might explain the increased mixing observed when the flow from linear arrays of rectangular nozzles is synchronized by edge tones as observed by Krothapalli ${ }^{4}$ or by screech Taghavi and Raman', and Raman and Taghavi ${ }^{2,3}$ since eddies are the primary mechanism that transfer energy from the mean now to the large turbulent structures. 
A linear instability model for a large span wise multinozzle region where the disturbance environment can be investigated using a two dimensional perturbation of the mean flow has been presented. The results indicate that an instability wave can occur and that this type of disurbrance has a large growth rate. In all the cases studied the most unstable wave has the same periodicity as the nozzle array.

It is conjectured that multiple supersonic rectangular jets phase-locked by screech or subsonic jets phase-locked by edge tones may exhibit a high growth rates downstream of the nozzles. Consequently, the model may explain the increase in mixing observed in multiple jets phase locked by screech or edge tones.

This work was conducted with the expectation that multi-jets with synchronized screech could provide increased mixing and reduced aerodynmaic acoustic noise. The model may be of significant scientific and engineering value in the quest to understand and construct supersonic mixer-ejector nozzles.

Table I. Calculation results at $\left(\omega_{1}\right)_{\max }$

\begin{tabular}{|c|c|c|c|c|c|c|c|c|}
\hline$M$; & $\Lambda$ & $\frac{1}{4 x}$ & $c_{1}$ & $c_{r}$ & $\Gamma$ & $\boldsymbol{k}$ & $\left(\omega_{1}\right)_{\operatorname{mex}}$ & $L *$ \\
\hline$\overline{0.5}$ & 1.24295 & 5.0 & 0.9 & $.2 .878747 \overline{\mathrm{E}}-1$ & $9.755581 \mathrm{E} 3$ & 1.205 & 0.54225 & $3.6605 \mathrm{E}-4$ \\
\hline 0.8 & 1.24295 & 5.0 & 0.8 & $-2.551930 \mathrm{E}-1$ & $2.955246 \mathrm{E}-2$ & 1.345 & 0.538 & $3.6605 E-4$ \\
\hline 1.25 & 1.294735 & 4.0 & 0.6 & $-2.475852 \mathrm{E}-1$ & $1.028344 \mathrm{E}-1$ & 2.06 & 0.618 & $5.4908 \mathrm{E}-3$ \\
\hline 1.3 & 1.28551 & 4.15 & 0.6 & $-2.584690 \mathrm{E}-1$ & $3.495140 \mathrm{E}-2$ & 1.935 & 0.5805 & $5.6555 \mathrm{E}-3$ \\
\hline 1.35 & 1.22414 & 5.5 & 0.6 & $-1.648727 \mathrm{E}-1$ & $3.762793 \mathrm{E}_{-2}$ & 2.06 & 0.4785 & $7.1380 E_{-}-3$ \\
\hline 1.4 & 1.24295 & 5.0 & 0.6 & $-2.084984 \mathrm{E}-1$ & $7.771379 \mathrm{E}-2$ & 1.41 & 0.423 & $3.6605 E_{-4}$ \\
\hline 1.4 & 1.23649 & 5.16 & 0.6 & $-1.860186 \mathrm{E}-1$ & $1.184881 \mathrm{E}-1$ & 1.935 & 0.411 & $6.7647 \mathrm{E}-3$ \\
\hline 1.45 & 1.173897 & 7.5 & 0.5 & $-2.394745 \mathrm{E}-2$ & $2.976108 \mathrm{E}-2$ & 2.060 & 0.515 & $9.3344 E-3$ \\
\hline 1.5 & 1.19688 & 6.43 & 0.5 & $-9.262075 \mathrm{E}-2$ & $6.455086 \mathrm{E}_{-2}$ & 1.91 & 0.411 & $8.1593 \mathrm{E}-3$ \\
\hline 1.55 & 1.139382 & 10.0 & 0.4 & $8.287612 \mathrm{E}-2$ & $9.056775 \mathrm{E} 2$ & 2.245 & 0.449 & $1.2079 \mathrm{E}-2$ \\
\hline 1.6 & 1.160343 & 8.32 & 0.4 & $9.901901 \mathrm{E}-3$ & $1.042738 \mathrm{E}-1$ & 2.240 & 0.448 & $1.0234 \mathrm{E}-3$ \\
\hline 1.65 & 1.1258595 & 11.5 & 0.3 & $8.145849 \mathrm{E}-2$ & $3.566117 \mathrm{E}_{-2}$ & 2.55 & 0.3825 & $1.3727 E_{-}-2$ \\
\hline 1.7 & 1.14881 & 9.16977 & 0.3 & $1.510411 \mathrm{E}-2$ & $9.125563 \mathrm{E}-2$ & 2.615 & 0.39225 & $1.1168 \mathrm{E}-2$ \\
\hline 1.75 & 1.111395 & 13.7 & 0.3 & $1.772602 \mathrm{E}-1$ & $9.963684 \mathrm{E}-3$ & 1.89 & 0.2835 & $1.6143 \mathrm{E} 2$ \\
\hline 1.8 & 1.13665 & 10.27 & 0.3 & $7.961790 \mathrm{E}-2$ & $4.183396 \mathrm{E}-3$ & 2.095 & 0.31425 & $1.2376 \mathrm{E}_{-2}$ \\
\hline
\end{tabular}




\section{Appendix A: Formulation of the problem}

Let $(U(y), 0,0)$ be the velocity of a steady planeparallel flow, where the $x$-axis is in the direction of the flow and

$$
U(y)=\bar{U}+\frac{\Delta U}{2} h(y)
$$

where $U_{1}$ is the velocity outside the jet, $U_{2}$ is the mean centerline jet velocity, $\vec{U}=\frac{U_{1}+U_{2}}{2}, \Delta U=U_{2}-U_{1}$, and $h(y)$ is the velocity profile function which varies from -1 to 1 .

The flow field is perturbed by introducing wave disturbances in the velocity and pressure with amplitudes that are a function of $\hat{y}$. Thus,

$$
\begin{aligned}
& (\tilde{u}, \tilde{v}, \tilde{w}, \tilde{p}) \\
= & (\breve{u}(\hat{y}), \breve{v}(\hat{y}), \breve{w}(\hat{y}), \breve{p}(\hat{y})) \exp [i(\hat{k} \hat{x}+\hat{\ell} z-\hat{w} \tau)] .
\end{aligned}
$$

Where

$$
\begin{aligned}
\hat{k} & =k L^{*}, \\
\hat{\imath} & =\ell L^{*}, \\
\hat{\omega} & =\frac{\omega L^{*}}{\Delta U}, \\
\hat{\omega} & =\frac{\omega}{k \Delta U}=\frac{c}{\Delta U}=\check{c},
\end{aligned}
$$

and we define $\hat{c}$ as follows

$$
\check{c}=\frac{c}{\Delta U}=\frac{\bar{U}}{\Delta U}+\frac{\hat{c}}{2} .
$$

By definition $\hat{k}$ is real positive number that represents the wavenumber in the $x$-direction, $\hat{\ell}$ is the wavenumber in the $z$-direction, $\hat{c}_{r}$ is the relative phase velocity, and $\hat{\omega}_{i}=\frac{\dot{k} \dot{c}_{1}}{2}$ is the amplification rate of the disturbance.

From the equations of motion if nonlinear and viscous terms are neglected one can obtain an equation for the $y$-component of the perturbation velocity as follows:

$$
\begin{aligned}
\breve{v}^{\prime \prime} & -\breve{v}^{\prime}\left(\frac{\hat{T}^{\prime}}{\hat{T}}+\frac{A^{\prime}}{A}\right) \\
& -\check{v}\left[\frac{h^{\prime \prime}}{(h-\hat{c})}+A i \hat{k}-\left(\frac{\hat{T}^{\prime}}{\hat{T}}+\frac{A^{\prime}}{A}\right) \frac{h^{\prime}}{(h-\hat{c})}\right]=0
\end{aligned}
$$

$\hat{y}$

where the primes denote differentiation with respect to

$$
\begin{array}{r}
A=-i \hat{k}-i \frac{\hat{\ell}^{2}}{\hat{k}}+m^{2} i \hat{k} \frac{(h-\hat{c})^{2}}{4} \\
A^{\prime}=2 m^{2} i \hat{k} \frac{(h-\hat{c}) h^{\prime}}{4}
\end{array}
$$

$$
m^{2}=\frac{m_{1}^{2}}{\hat{T}}
$$

and from Crocco's Equation ${ }^{18}$

$$
\begin{aligned}
\hat{T}(y)= & \frac{T(y)}{T_{1}} \\
= & \frac{T_{2}}{T_{1}}+\frac{(1+h(y))}{2}\left(1-\frac{T_{2}}{T_{1}}\right) \\
& -\frac{1}{2}\left(m_{1}\right)^{2}(\gamma-1) \frac{(h(y)+1)(h(y)-1)}{4}
\end{aligned}
$$

where

$$
m_{1}=\frac{\Delta U}{a_{1}}=\frac{\Delta U}{a_{2}} \frac{\sqrt{T_{2}}}{\sqrt{T_{1}}}=m_{2} \frac{\sqrt{T_{2}}}{\sqrt{T_{1}}} .
$$

In this paper, the velocity profile function, $h(y)$, is periodic such that

$$
h(y+2 \pi)=h(y) .
$$

The velocity profile $h(y)$ is not any exact solution of the Navier-Stokes equation, but it can be considered as a simple model of some real periodic flow.

The velocity profile $h(y)$ discussed herein is given by

$$
h(y)=1-2 f(y)
$$

where the function $f(y)$ is given by

$$
\begin{gathered}
f(y)=\frac{1}{\left[1+\left(\sinh \left(\frac{\eta}{\sinh (1)}\right)\right)^{18}\right]}, \\
\eta=\Lambda\left(-1+\frac{y}{\pi}\right),
\end{gathered}
$$

values of $\Lambda$ for the ratios of $\left(s / w_{N}\right)$ used herein are given in Table II and $y$ goes from 0.0 to $2 \pi$. The profile function $f(y)$ is adapted from an equation used by Monkewitz ${ }^{16}$ in a study of the absolute and convective instability of two-dimensional wakes. Only twodimensional disturbances will be considered. A schematic of the nozzle geometry is shown in Figure 1. A typical velocity profile using $\Lambda=1.5$ is shown in Figure 2. 
Appendix B: Floquet-Bloch theory

Since the basic flow velocity profile, $f(y)$, is periodic, equation (A1) is an example of a Floquet-Bloch problem. The mathematics of solving Floquet-Bloch type problems is discussed by Ince ${ }^{19}$, Hochstadt ${ }^{20}$, and Zwillinger ${ }^{21}$. Applications to solid state physics are discussed by Sachs ${ }^{22}$, Brillouin ${ }^{23}$, and Dekker ${ }^{24}$. Applications to spatially periodic flow are discussed by Lorenz ${ }^{25}$, Green $^{26}$, Beaumont ${ }^{17}$, and Gotoh ${ }^{27,28}$.

The paper by Beaumont ${ }^{17}$ and the description of the Floquet-Bloch theorem by Hochstadt ${ }^{20}$ were particularly useful in guiding this research.

A survey of the spatially periodic flow literature is presented by K. Gotoh and M.Y. Yamada ${ }^{29}$.

The second order differential equation can be described by a system of first order differential equations. Let

$$
\begin{aligned}
\breve{v} & =x_{1} \\
\breve{v}^{\prime} & =x_{2}
\end{aligned}
$$

so that Eq. Al can be rewritten as the system

$$
X^{\prime}=\left(\begin{array}{cc}
0 & 1 \\
D & C
\end{array}\right) X
$$

where

$$
C=\left(\frac{\hat{T}^{\prime}}{\hat{T}}+\frac{A^{\prime}}{A}\right)
$$

and

$$
D=\left[\frac{h^{\prime \prime}}{(h-\hat{c})}+A i \hat{k}-\left(\frac{\hat{T}^{\prime}}{\hat{T}}+\frac{A^{\prime}}{A}\right) \frac{h^{\prime}}{(h-\hat{c})}\right]
$$

If $\Phi(y)$ is a fundamental matrix solution of equation ( (B1)) such that

$$
\Phi(0)=\mathbf{I}
$$

where $I$ is the identity matrix, then from the FloquetBloch theorem

$$
\Phi(y+2 \pi)=\Phi(y) \Phi(2 \pi)
$$

We now introduce two solutions of equation ( B1) with initial values at $y=0.0$

$$
\Phi(0)=\left[\begin{array}{ll}
\phi_{1}(0) & \phi_{2}(0) \\
\phi_{1}^{\prime}(0) & \phi_{2}^{\prime}(0)
\end{array}\right]=\left[\begin{array}{ll}
1 & 0 \\
0 & 1
\end{array}\right]
$$

Next we seek the eigenvalues of $\Phi(2 \pi)$

$$
\begin{aligned}
& |\Phi(2 \pi)-\mu \mathbf{I}| \\
= & \left|\begin{array}{cc}
\phi_{1}(2 \pi)-\mu & \phi_{2}(2 \pi) \\
\phi_{1}{ }^{\prime}(2 \pi) & \phi_{2}{ }^{\prime}(2 \pi)-\mu
\end{array}\right| \\
= & \mu^{2}-\left(\phi_{1}(2 \pi)+\phi_{2}^{\prime}(2 \pi)\right) \mu \\
& +\left(\phi_{1}(2 \pi) \phi_{2}{ }^{\prime}(2 \pi)-\right. \\
& \left.\phi_{2}(2 \pi) \phi_{1}{ }^{\prime}(2 \pi)\right) \\
= & \mu^{2}-\left(\phi_{1}(2 \pi)+\phi_{2}{ }^{\prime}(2 \pi)\right) \mu+1=0
\end{aligned}
$$

Since

$$
\phi_{1}(2 \pi) \phi_{2}{ }^{\prime}(2 \pi)-\phi_{2}(2 \pi) \phi_{1}^{\prime}(2 \pi)=|\Phi(2 \pi)|=|\Phi(0)|=1
$$
form

The independent solutions of equation (B1) have the

$$
\phi=X(y) \exp \left(\frac{\log (\mu)}{2 \pi} y\right)=X(y) \exp (\Gamma y)
$$

The parameter $\Gamma$ specifies the period of the eigenfunction $\phi$. If $\Gamma$ is real the eigenfunction grows or decays at infinity. Consequently, only imaginary values of $\Gamma$ are acceptable. Thus the eigenfunction oscillates in space and is called a continuous mode. The disturbance with $\Gamma_{i}=1 / n$, where $n$ is a nonzero integer, has a period $2 n \pi$. One with $\Gamma_{i}=0$ has the same period $2 \pi$ as the main flow, while an irrational value of $\Gamma_{i}$ means the disturbance is aperiodic. Note that the parameter $\Gamma$ does not appear in the flow equation, but is due to the Floquet-Bloch theorem.

Solutions of $\mathrm{Bl}$ are thus of the form

$$
\begin{aligned}
& X_{1}(y+2 \pi)=\mu_{1} X_{1}(y) \\
& X_{2}(y+2 \pi)=\mu_{2} X_{2}(y)
\end{aligned}
$$

where $\mu_{1}$ and $\mu_{2}$ represent the zeros of (B2), provided they are distinct.

In general, these solutions will not be periodic.

Conditions for periodic solutions can be found as follows

Let $\mu_{1}=e^{i \theta_{1}}$ and $\mu_{2}=e^{-i \theta_{1}}$.

Then from equation (B2)

$$
\cos \left(\theta_{i}\right)=\phi_{1}(2 \pi)+\phi_{2}{ }^{\prime}(2 \pi)=\delta / 2
$$

Consequently, for a solution to be periodic $\delta$ must be real and $|\delta|$ smaller than 2 .

The constants $\mu$ are termed the characteristic multipliers of the Floquet-Bloch system (B1) and the corresponding characteristic exponents are determined by the relation $\Gamma=\Gamma_{r}+i \Gamma_{i}=\frac{\log (\mu)}{2 \pi}=\frac{\theta_{r}}{2 \pi}+i \frac{\theta_{r}}{2 \pi}$. 


\section{References}

${ }^{1}$ R. Taghavi and G. Raman. Enhanced mixing of multiple supersonic rectangular jets by synchronized screech. AIAA Journal, $32: 2477-2480,1994$.

${ }^{2}$ Ganesh Raman and Ray Taghavi. Resonant interaction of a linear array of supersonic rectangular jet: an experimental study. AIAA-95-0510 paper presented at the S9rd Aerospace Sciences Meeting and Exhibit January 912, Reno, NV, 1995.

${ }^{3}$ Ganesh Raman and Ray Taghavi. Resonant interaction of a linear array of supersonic rectangulary jets: an experemental study. J. Fluid Mech, 309 :93-111, 1996.

A. Krothapalli, K. Karamcheti, Y. Hsia, and D. Baganoff. Edge tones in high-speed flows and their application to multiple-jet mixing. AIA A Journal, 21 No. 7:937-938, July 19831983.

${ }^{5}$ A. Krothapalli, D. Baganoff, and K. Karamcheti. Development and structure of a rectangular jet in a multiple jet configuration. AIAA Journal, 18 No. 8:945-950, August 19801980.

- E. Villermaux and E.J. Hopfinger. Periodically arranged co-flowing jets. J. Fluid Mech., 263 No.:63-92, 1994.

${ }^{7}$ E. Villermaux, Y. Gagne, and E.J. Hopfinger. Self sustained oscillations and collective behaviours in a lattice of jets. Applied Scientific Research, 51 :243-248, 1993.

- D. Papamoschou and A. Roshko. Observations of supersonic free shear layers. AIAA 86-0162, 1986.

- Dimitri Papamoschou. Experimental Investigation of Heterogeneous Compressible Shear Layers. PhD thesis, California Institute of Technology, Pasadena, California, 1987.

${ }^{10} \mathrm{D}$. Papamoschou and A. Roshko. The compressible turbulent shear layer: an experimental study. J. Fluid Mech., 197 No.:453-477, 1988.

11 N. Chinzei, G. Masuya, T. Komuro, A. Murakami, and D. Kudou. Spreading of two-streams supersonic turbulent mixing layers. The Physics of Fluids, 29 No.5:1345-1347, 1986.

${ }^{12}$ M. Samimy and G. S. Elliott. Effects of compressibility on the structure of free shear layers. AIA A 88-3054, 1988.

${ }^{13}$ Hans Gropengiesser. On the stability of free shear layers in compressible flows. (in German) Beitrag zur Stabilitat freier Grenzschichten in kompressiblen Medien; Deutsche Luft. und Raumfahrt, Report DLR FB-69-25, 123 pp., 1969. Also NASA TT F-12,786 (1970) and N70-32468.

$14 \mathrm{~S}$. A. Ragab and J. L. Wu. Instabilities in the free shear layer formed by two supersonic streams. AIAA Paper 88$0038,1988$.

${ }^{15}$ Mei Zhuang, T. Kubota, and P. E. Dimotakis. On the instability of inviscid, compressible free shear layers. Conference Proc. 1st National Fluid Dyn. Cong. July 25-28 Cincinnati, Ohio, 768-773, 1988.

${ }^{16}$ Peter A. Monkewitz. The absolute and convective nature of instability in two-dimensional wakes at low reynolds numbers. Phys. Fluids, 31No.5:999-1006, May 1988.

${ }^{17} \mathrm{D}$. N. Beaumont. The stability of spatially periodic flows. J. Fluid Mech., $108: 461-474,1981$.

18 Hermann Schlichting. Boundary-Layer Theory. McGrawHill Book Company, 1968.

$19 \mathrm{E}$. L. Ince. Ordinary differential equations. Dover, 1926,1956. pp. 381-382.
${ }^{20}$ Harry Hochstadt. Differential Equations. Dover, 1963. pp. 195-200.

${ }^{21}$ Daniel Zwillinger. Handbook of Differential Equations. Academic Press, 1992. pp. 448-118.

${ }^{22}$ Mendel Sachs. Solid State Theory. Dover, 1963. pp. 189198.

${ }^{23}$ L. Brillouin. Wave Propagation in Periodic Structures. Dover Publications, Inc., 1946. pp. 172-186.

${ }^{24}$ Adrianus J. Dekker. Solid State Physics. Prentice-Hall, Inc., 1962. pp.238-250.

${ }^{25}$ Edward N. Lorenz. Barotropic instability of rossby wave motion. Journal of the Atmospheric Sciences, 29 :258-264, March 1972.

${ }^{28} \mathrm{~J}$. S. A. Green. Two-dimensional turbulence near the viscous limit. J. Fluid Mech, 62 :273-287, 1974.

${ }^{27}$ Kanefusa Gotoh, Michio Yamada, and Jiro Mizushima. The theory of stability of spatially periodic parallel flows. J. Fluid Mech., 127:45-58, 1983.

${ }^{28}$ Michio Yamada. Nonlinear stability theory of spatially periodic parallel flows. Journal of the Physical Society of Japan, 55No.9:3073-3079, September 1986.

${ }^{29} \mathrm{~K}$. Gotoh and M. Yamada. Stability of spatially periodic flows. In unknown, editor, Encyclopedia of Fluid Mechanics, chapter 19, pages 589-610, Houston, Tex: Gulf, 1986. 


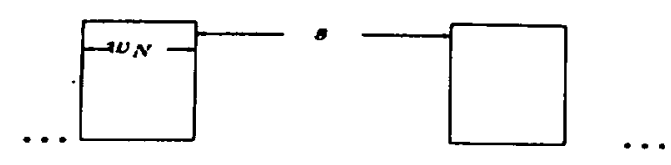

Figure 1. Nozzle configuration.

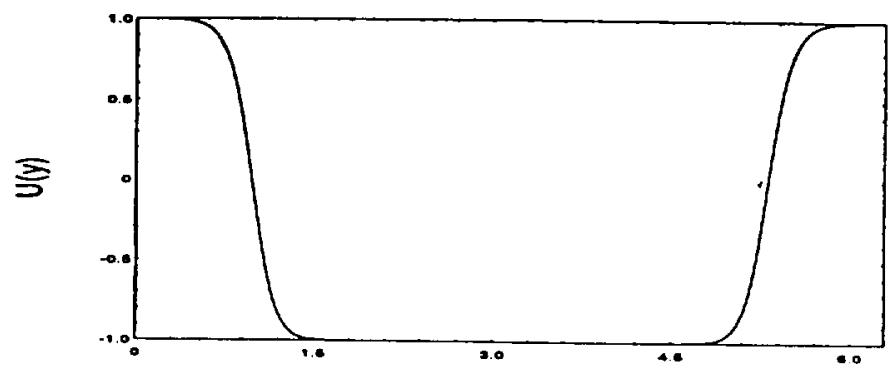

Figure 2. Typical velocity profile. $(\Lambda=1.5 \mathrm{~s} / \mathrm{h}=2.23$ )

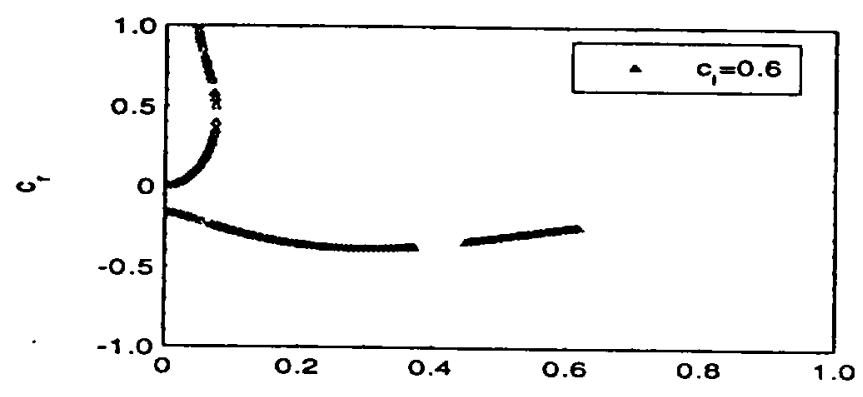

$\omega$.

Figure 3(a). Eigenvalue or verses growth rate $\omega_{i}=\frac{k c_{i}}{2}\left(m_{2}=1.25 \mathrm{~s} / w_{N}=4\right)$.

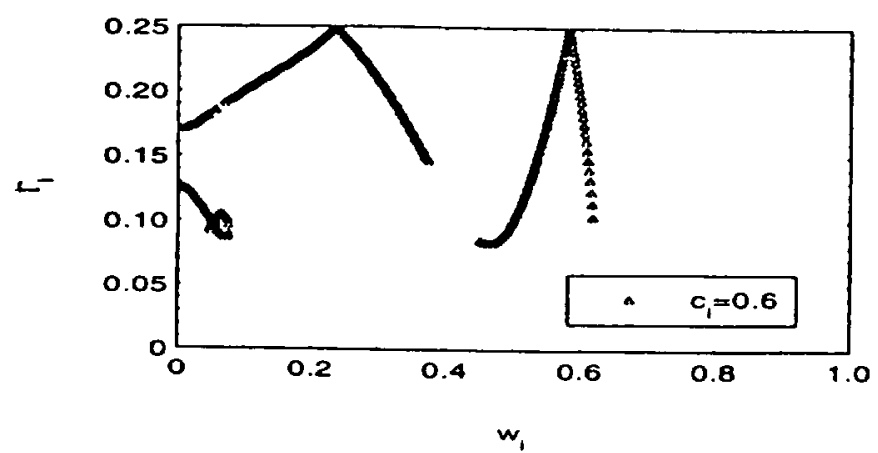

Figure $3(b)$. $\Gamma_{i}$ verses growth rate $\omega_{i}=\frac{A_{i}}{2}\left(r_{2}=1.25 \mathrm{~N} / w_{N}=4\right)$.

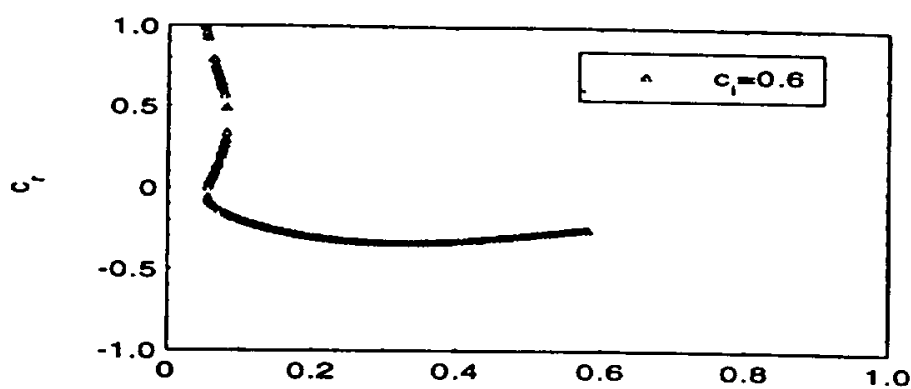

$\omega_{1}$

Figure 4(a). Eigenvalue or verges growth rate $\omega_{i}=\frac{k \cdot c_{i}}{2}\left(m_{2}=1.3 \quad s / w_{N}=4.15\right)$.

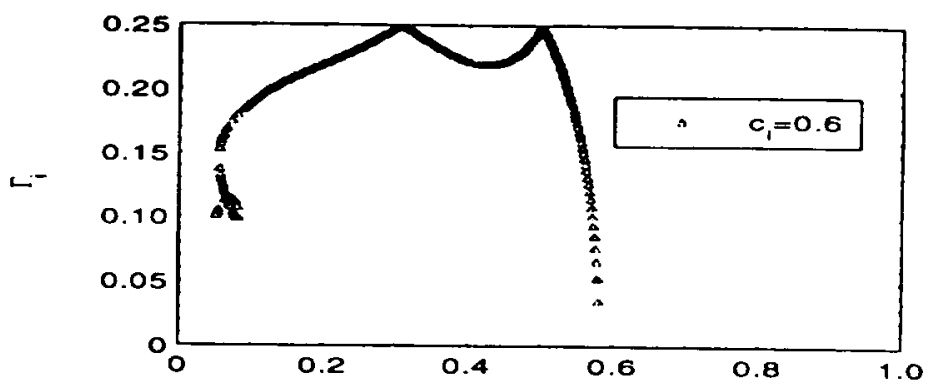

$\omega_{1}$

Figure 4(b). $\Gamma_{i}$ verses growth rate $\omega_{i}=\frac{k \cdot c_{i}}{2}\left(m_{2}=1.3 \mathrm{~s} / w_{N}=4.15\right)$.

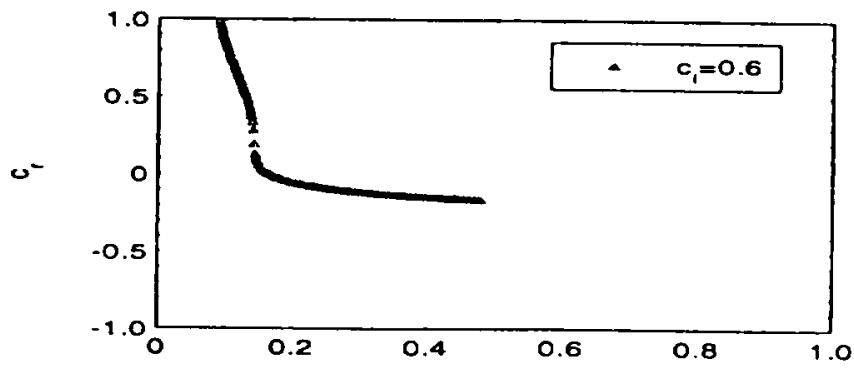

$\omega$

Figure 5(a). Eigenvalue or verses growth rate $\omega_{i}=\frac{k c_{i}}{2}\left(m_{2}=1.35 s / w_{N}=5.5\right)$.

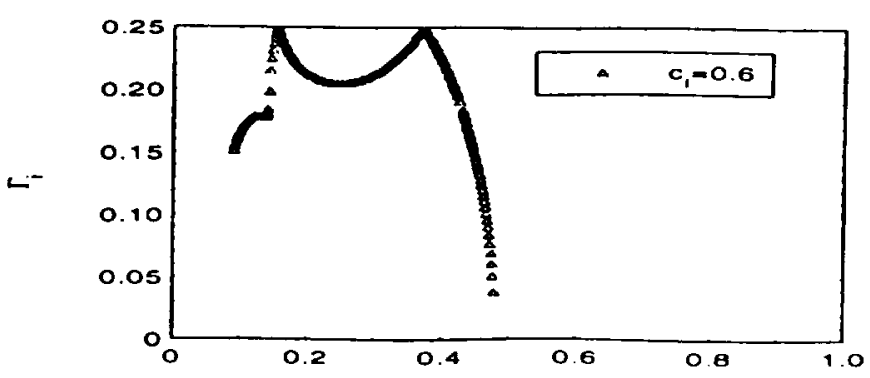

$\omega$,

Figite 5(1,). $\Gamma_{i}$ versos prowll rate $\omega_{i}=\frac{k_{2}}{2}\left(m_{2}=1.35 * / \cdots N=5.5\right)$. 


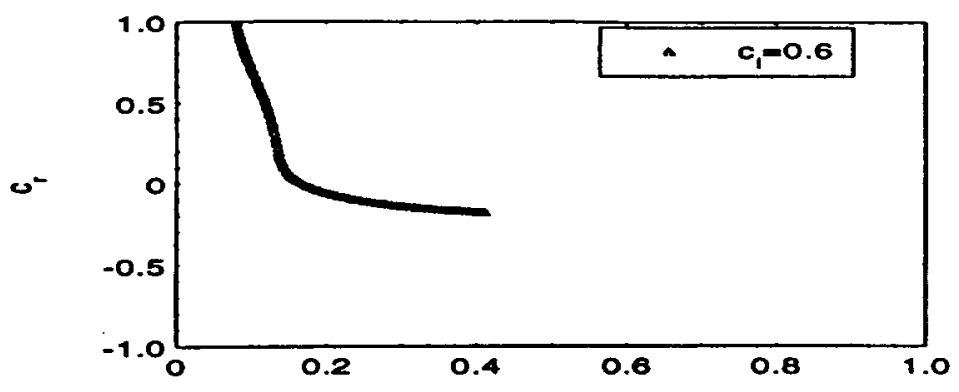

$\infty$

Figure 6(a). Eigenvalue or verses growth rate $\omega_{i}=\frac{k c_{i}}{2}\left(m_{2}=1.4 \quad s / w_{N}=5.16\right)$.

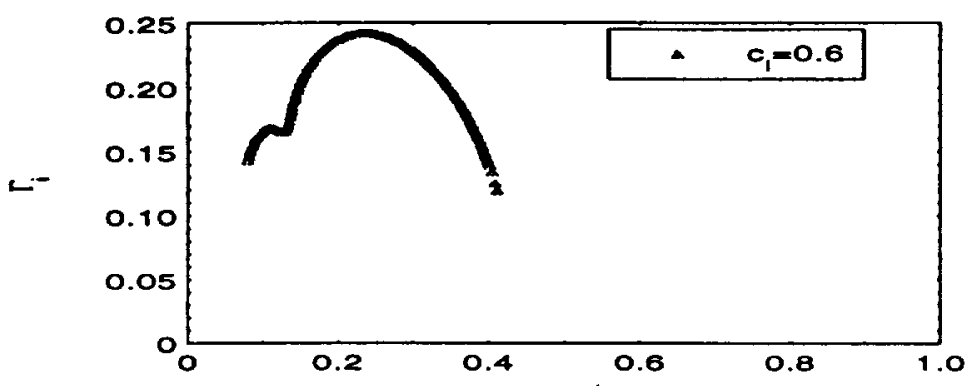

$\omega_{1}$

Figure $6(\mathrm{~b})$. $\Gamma_{i}$ verses growth rate $\omega_{i}=\frac{k c_{i}}{2}\left(m_{2}=1.4 \quad s / w_{N}=5.16\right)$.

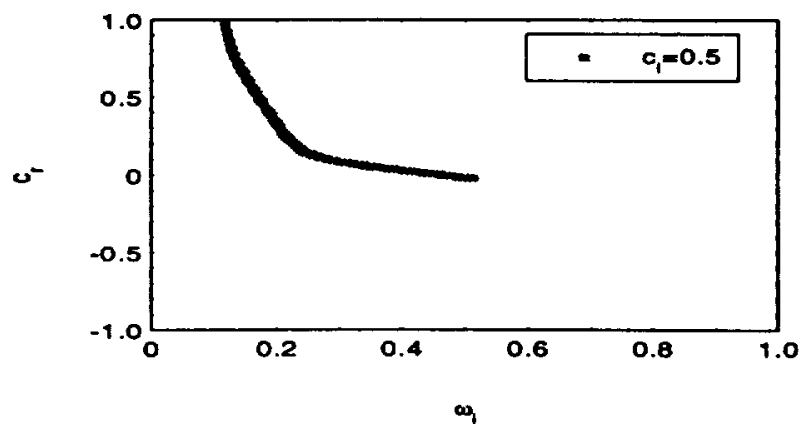

Figure $7(a)$. Eigenvalue $c_{r}$ verses growth rate $\omega_{i}=\frac{k c_{i}}{2}\left(m_{2}=1.45 \cdot / w_{N}=7.5\right)$.

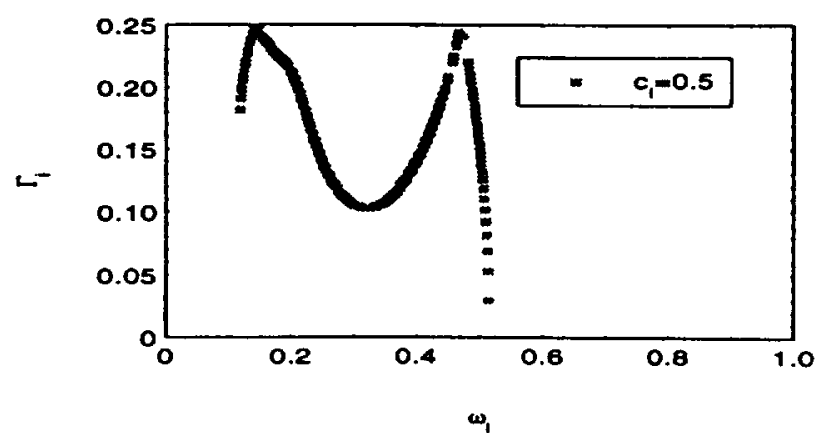

Figure $7(b)$. $\Gamma_{i}$ verses growth ratc $\omega_{i}=\frac{k_{i} c_{i}}{2}\left(m_{2}=1.45 \% / w_{N}=7.5\right)$.

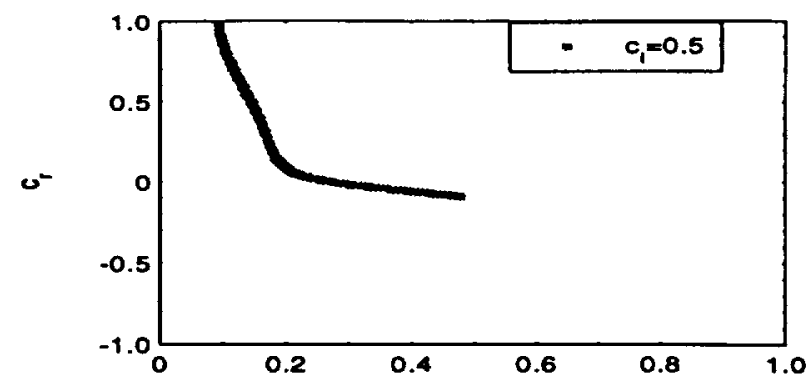

$\infty$

Figure 8(a). Eigenvalue cr verses growth rate $\omega_{i}=\frac{k c_{i}}{2}\left(m_{2}=1.5 \quad \mathrm{~s} / w_{N}=6.43\right)$.

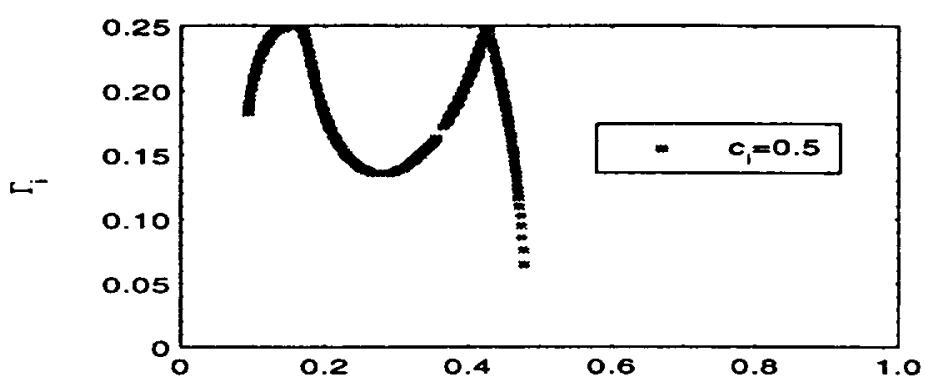

$\omega$

Figure $8(b)$. $\Gamma_{i}$ verses growth rate $\omega_{i}=\frac{k c_{i}}{2}\left(m_{2}=1.5 s / w_{N}=6.43\right)$.

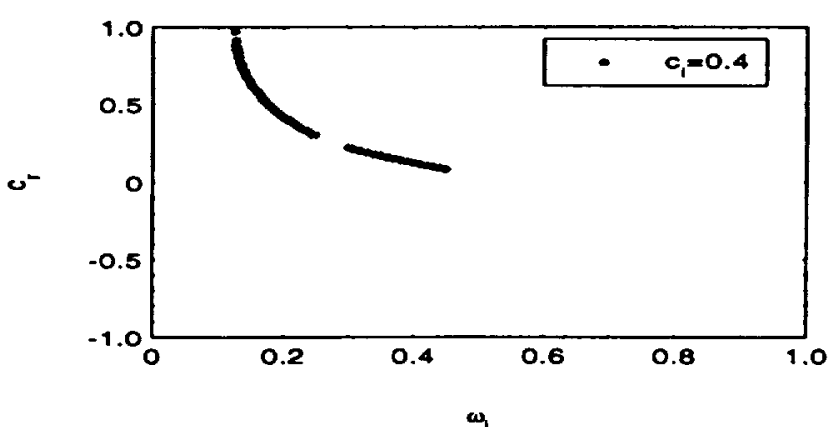

Figure 9(a). Eigenvalue or verses growth ratc $w_{i}=\frac{k c_{i}}{2}\left(m_{2}=1.55 \cdot / w_{N}=10\right)$.

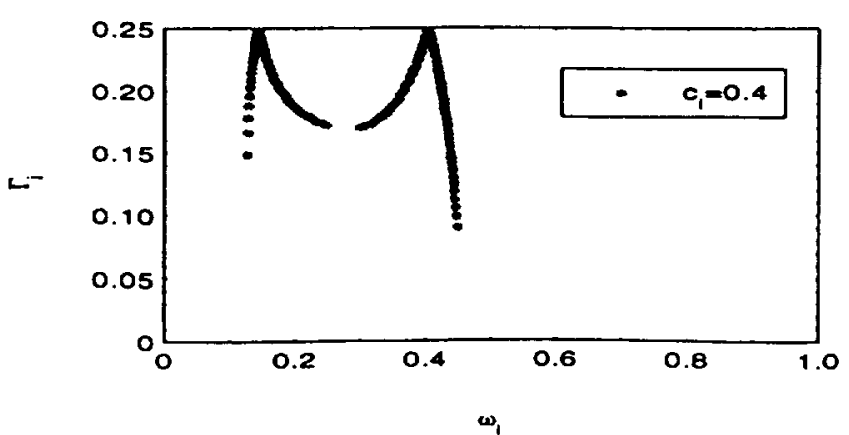

Figure $9(\mathrm{~b}) . \Gamma_{i}$ verses growth rate $w_{i}=\frac{k C_{i}}{2}\left(m_{2}=1.55 * / \omega_{N}=10\right)$. 


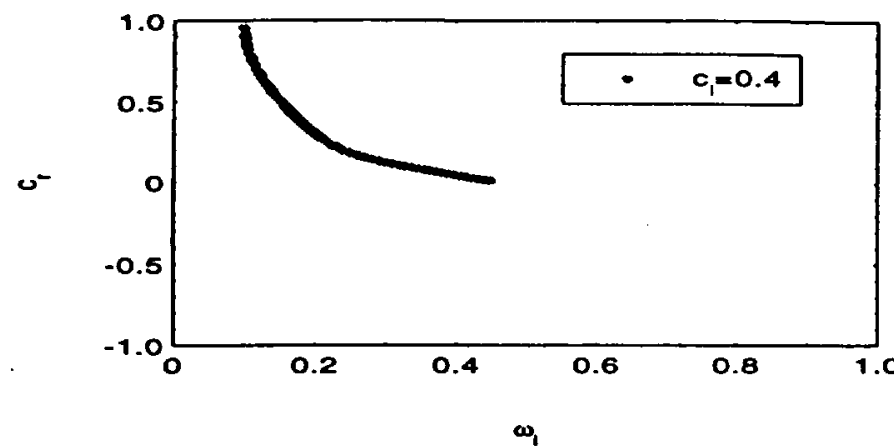

Figure 10 (a). Eigenvalue or verses growth rate $\omega_{i}=\frac{k c_{i}}{2}\left(m_{2}=1.6 \cdot / w_{N}=8.32\right)$.

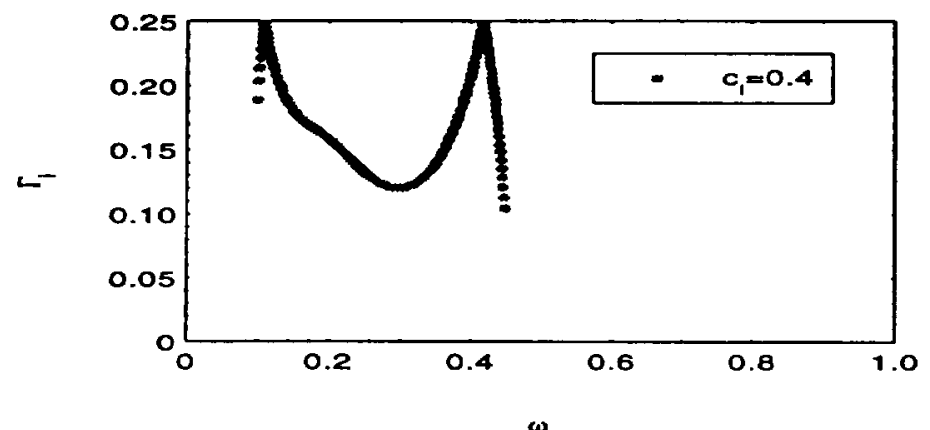

Figure $10(b) . \Gamma_{i}$ verses growth rate $\omega_{i}=\frac{k c_{i}}{2}\left(m_{2}=1.6 s / w_{N}=8.32\right)$.

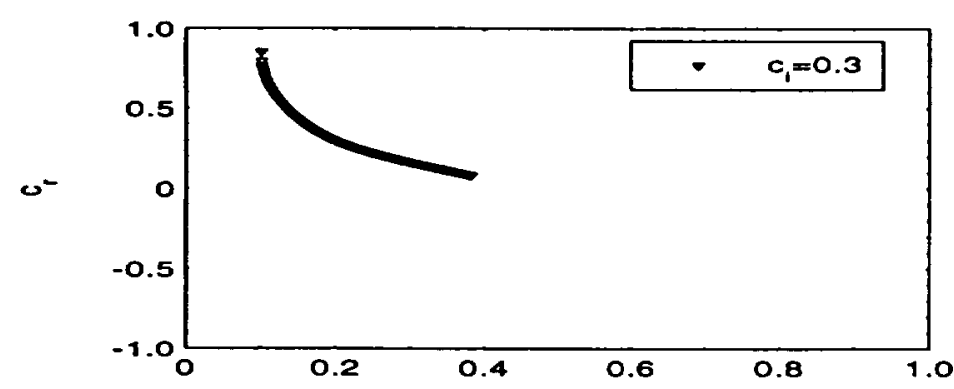

$\omega_{1}$

Figure 11(a). Eigenvalue or verses growth rate $\omega_{i}=\frac{k_{i}}{2}\left(m_{2}=1.65 \mathrm{~s} / w_{N}=11.5\right)$.

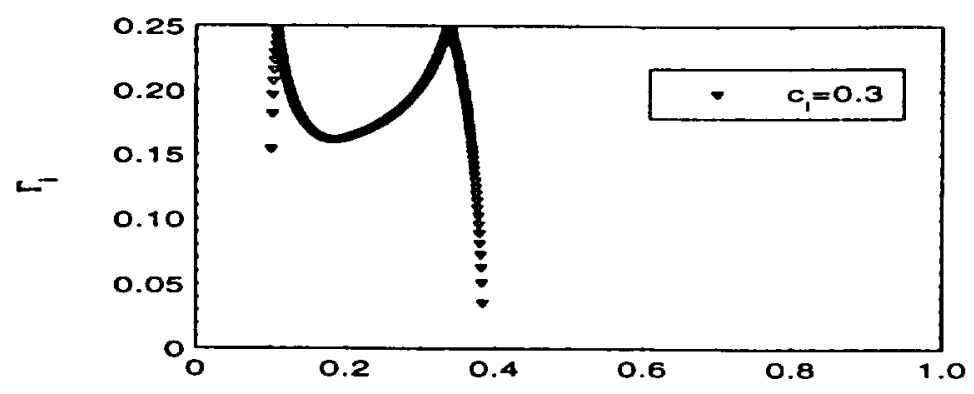

$\omega_{1}$

Figure 11(b). $\Gamma_{i}$ verses frowth rate $\omega_{i}=\frac{k_{i} c_{i}}{2}\left(m_{2}=1.65 .4 \% N=11.5\right)$.

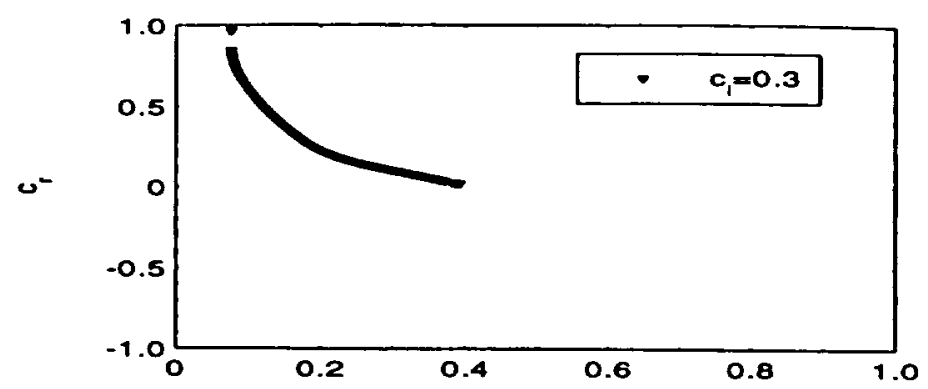

$\omega_{1}$

Figure 12(a). Eigenvalue or verses growth rate $\omega_{i}=\frac{k c_{i}}{2}\left(m_{2}=1.7 \cdot / w_{N}=9.169\right)$.

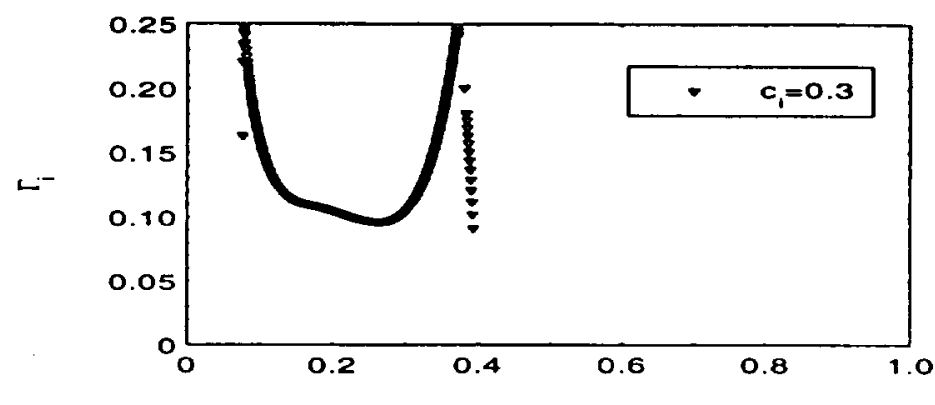

$\omega_{1}$

Figure 12(b). $\Gamma_{i}$ verses growth rate $w_{i}=\frac{k c_{i}}{2}\left(m_{2}=1.7, / w_{N}=9.169\right)$.

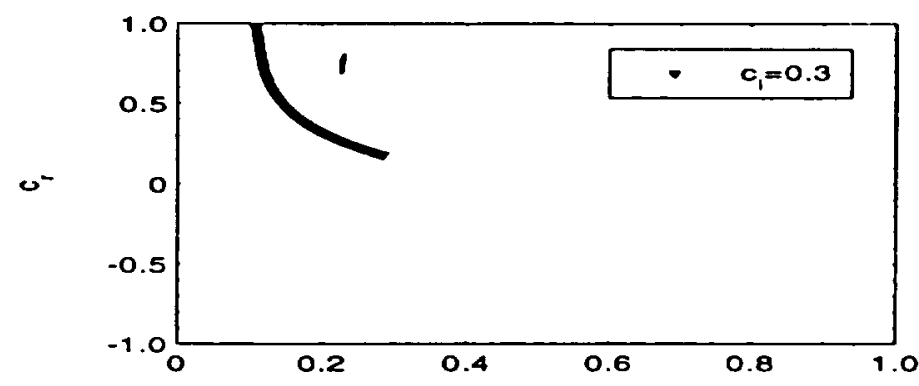

$\omega_{1}$

Figure 13(a). Eigenvalue $c_{r}$ verses growt/ rate $w_{i}=\frac{k c_{i}}{2}\left(m_{2}=1.75 \quad s / w_{N}=13.7\right)$.

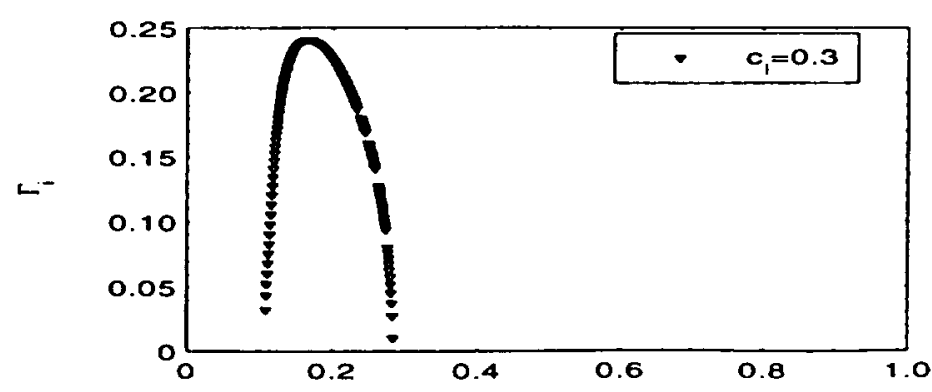

$\omega_{1}$

Figure $13(1$,$) . Fi verses growtl, rite$ $\omega_{i}=\frac{k_{2}}{2}\left(m_{2}=1.75 \% / \omega^{\prime}=1: 37\right)$. 


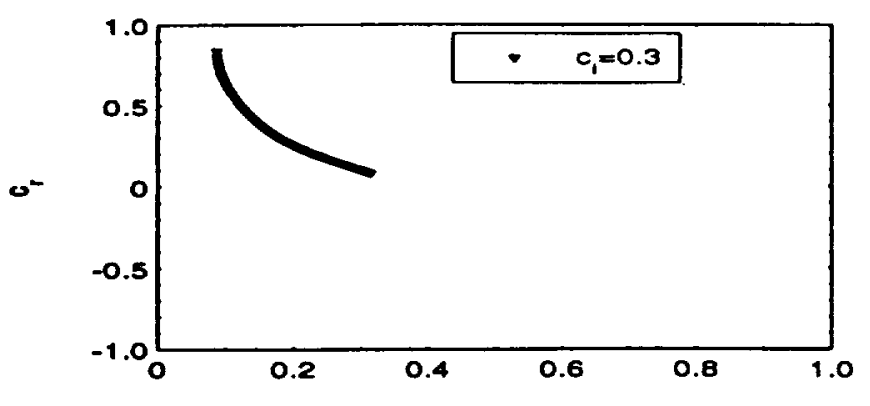

$\infty$

Figure 14(a). Eigenvalue or verses growth rate $\omega_{i}=\frac{k c_{i}}{2}\left(m_{2}=1.8 \quad \cdot / w_{N}=10.27\right)$.

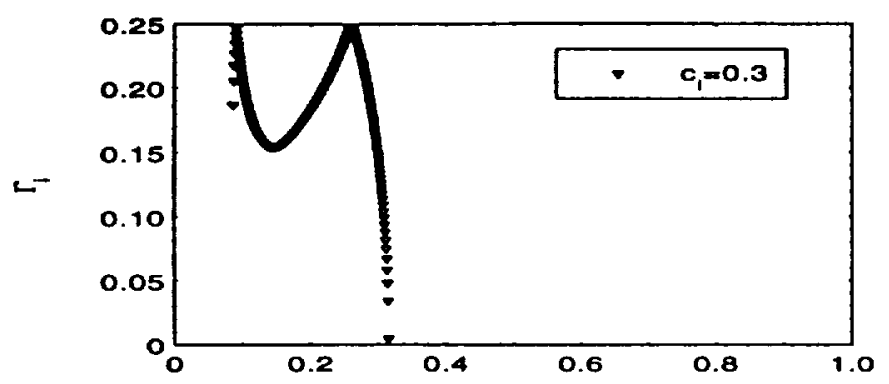

$\omega$

Figure 14(b). $\Gamma_{i}$ verses growth rate $\omega_{i}=\frac{k c_{i}}{2}\left(m_{2}=1.8 \quad s / w_{N}=10.27\right)$.

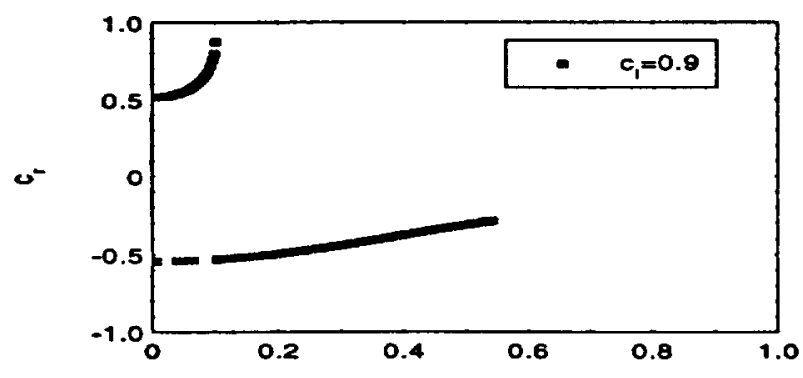

$\omega_{1}$

Figure 15(a). Eigenvalue cr verses growth rate $w_{i}=\frac{k c_{i}}{2}\left(m_{2}=0.5 \% / w_{N}=5\right)$.

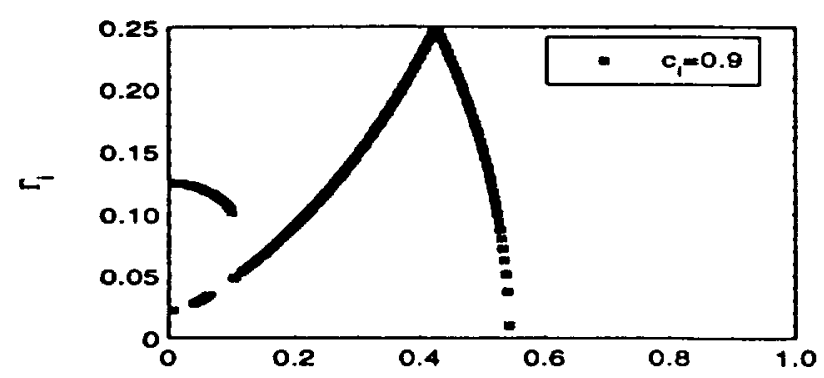

$\omega_{1}$

Figure 15(b). $\Gamma_{i}$ verses growth rate $\omega_{i}=\frac{k_{i}}{2}\left(m_{2}=0.5 \cdot / u_{N}=5\right)$.

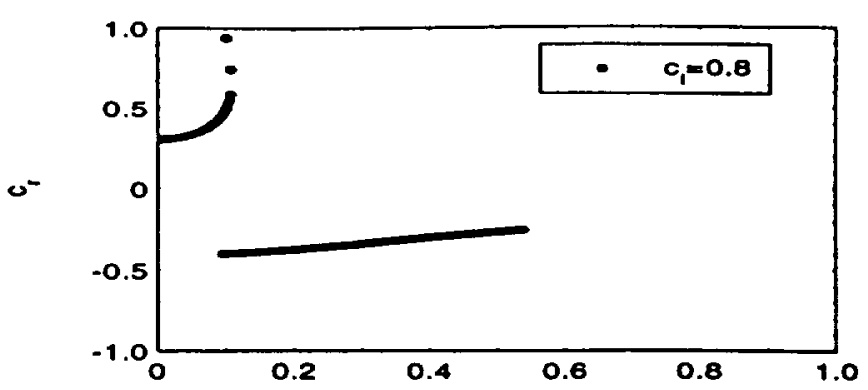

$\omega_{1}$

Figure 16(a). Eigenvalue or verses growth rate $\omega_{i}=\frac{k c_{i}}{2}\left(m_{2}=.8 \quad s / w_{N}=5\right)$.

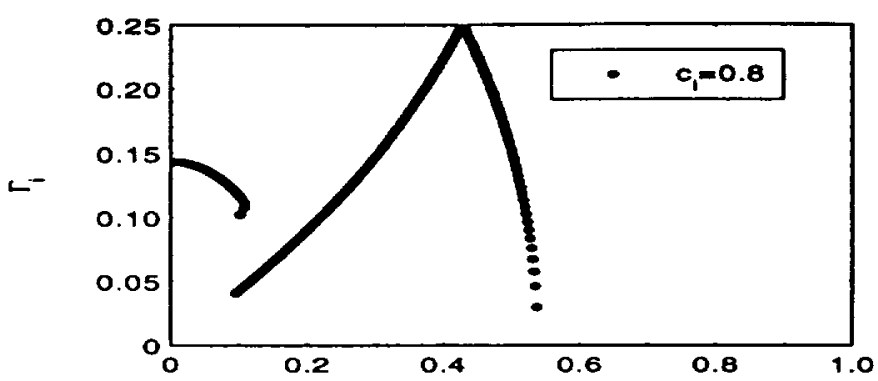

$\omega_{1}$

Figure $16(b) . \Gamma_{i}$ verses growth rate $\omega_{i}=\frac{k c_{i}}{2}\left(m_{2}=0.8 \quad / w_{N}=5\right)$.

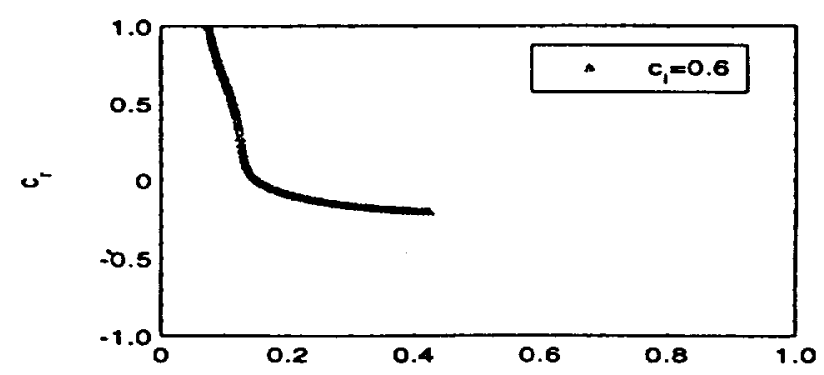

m

Figure 17 (a). Eigenvalue $c_{r}$ verses growth rate $w_{i}=\frac{k c_{i}}{2}\left(m_{2}=1.4: / w_{N}=5\right)$.

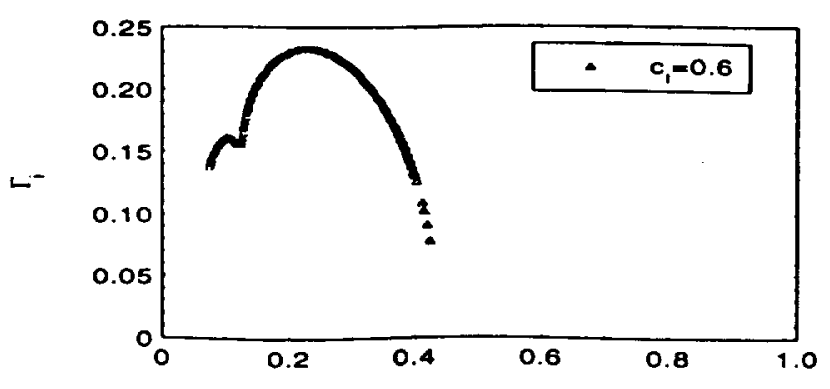

$\omega$

Fikure $17(b)$. $\Gamma_{i}$ verses growth rate $w_{1}=k_{2} \cdot\left(m_{2}=1.4 * / \omega_{N}=5\right)$. 



\begin{tabular}{|c|c|c|c|}
\hline \multicolumn{3}{|c|}{ REPORT DOCUMENTATION PAGE } & $\begin{array}{l}\text { Form Approved } \\
\text { OMB No. 0704-0188 }\end{array}$ \\
\hline \multicolumn{4}{|c|}{ 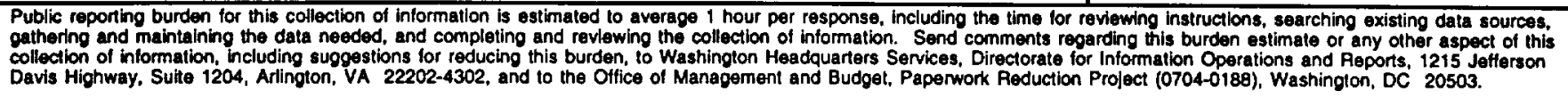 } \\
\hline 1. AGENCY USE ONLY (Leave blank) & $\begin{array}{r}\text { 2. AEPORT DATE } \\
\text { June } 1997 \\
\end{array}$ & \multicolumn{2}{|c|}{$\begin{array}{l}\text { 3. REPORT TYPE AND DATES COVERED } \\
\text { Technical Memorandum }\end{array}$} \\
\hline \multicolumn{3}{|c|}{$\begin{array}{l}\text { 4. TITLE AND SUBTITLE } \\
\text { Collective Interaction of a Compressible Periodic Parallel Jet Flow }\end{array}$} & \multirow{2}{*}{$\begin{array}{l}\text { 5. FUNDING NUMBERS } \\
\text { WU-537-05-21 }\end{array}$} \\
\hline \multicolumn{3}{|l|}{$\begin{array}{l}\text { 6. AUTHOA(S) } \\
\text { Jeffrey Hilton Miles }\end{array}$} & \\
\hline \multicolumn{3}{|c|}{$\begin{array}{l}\text { 7. PERFORMING ORGANIZATION NAME(S) AND ADDRESS(ES) } \\
\text { National Aeronautics and Space Administration } \\
\text { Lewis Research Center } \\
\text { Cleveland, Ohio } 44135-3191\end{array}$} & $\begin{array}{l}\text { 8. PERFORMING ORGANIZATION } \\
\text { REPORT NUMBER } \\
\text { E-10754 }\end{array}$ \\
\hline \multicolumn{3}{|c|}{$\begin{array}{l}\text { 9. SPONSORINGMONITORING AGENCY NAME(S) AND ADDRESS(ES) } \\
\text { National Aeronautics and Space Administration } \\
\text { Washington, DC 20546-0001 }\end{array}$} & $\begin{array}{l}\text { 10. SPONSORING/MONITORING } \\
\text { AGENCY REPORT NUMBER } \\
\text { NASA TM-107467 } \\
\text { AIAA-97-0150 }\end{array}$ \\
\hline \multicolumn{4}{|c|}{$\begin{array}{l}\text { 11. SUPPLEMENTARY NOTES } \\
\text { Prepared for the 35th Aerospace Sciences Meeting and Exhibit sponsored by the American Institute of Aeronautics and } \\
\text { Astronautics, Reno, Nevada, January 6-10, 1997. Responsible person Jeffrey Hilton Miles, organization code } 2660 \text {, } \\
\text { (216) 433-5909. }\end{array}$} \\
\hline \multicolumn{3}{|c|}{$\begin{array}{l}\text { 12a. DISTRIBUTIONAVAILABILITY STATEMENT } \\
\text { Unclassified - Unlimited } \\
\text { Subject Category } 34 \\
\text { This publication is available from the NASA Center for AeroSpace Information, (301) 621-0390. }\end{array}$} & 12b. DISTRIBUTION CODE \\
\hline \multicolumn{4}{|c|}{$\begin{array}{l}\text { A linear instability model for multiple spatially periodic supersonic rectangular jets is solved using Floquet-Bloch theory. } \\
\text { The disturbance environment is investigated using a two dimensional perturbation of a mean flow. For all cases large } \\
\text { temporal growth rates are found. This work is motivated by an increase in mixing found in experimental measurements of } \\
\text { spatially periodic supersonic rectangular jets with phase-locked screech. The results obtained in this paper suggests that } \\
\text { phase-locked screech or edge tones may produce correlated spatially periodic jet flow downstream of the nozzles which } \\
\text { creates a large span wise multi-nozzle region where a disturbance can propagate. The large temporal growth rates for } \\
\text { eddies obtained by model calculation herein are related to the increased mixing since eddies are the primary mechanism } \\
\text { that transfer energy from the mean flow to the large turbulent structures. Calculations of growth rates are presented for a } \\
\text { range of Mach numbers and nozzle spacings corresponding to experimental test conditions where screech synchronized } \\
\text { phase locking was observed. The model may be of significant scientific and engineering value in the quest to understand } \\
\text { and construct supersonic mixer-ejector nozzles which provide increased mixing and reduced noise. }\end{array}$} \\
\hline \multirow{2}{*}{\multicolumn{3}{|c|}{$\begin{array}{l}\text { 14. SUBJECT TERMS } \\
\text { Flow stability; Jets; Shear layers; Periodic variations; Spatial distribution; Phase velocity; } \\
\text { Floquet theorem; Wave propagation }\end{array}$}} & $\begin{array}{c}\text { 15. NUMBER OF PAGES } \\
12 \\
\end{array}$ \\
\hline & & & $\begin{array}{r}\text { 16. PAICE CODE } \\
\mathrm{A03}\end{array}$ \\
\hline $\begin{array}{l}\text { 17. SECURITY CLASSIFICATION } \\
\text { OF REPORT } \\
\text { Unclassified }\end{array}$ & $\begin{array}{l}\text { 18. SECURITY CLASSIFICATION } \\
\text { OF THIS PAGE } \\
\text { Unclassified }\end{array}$ & $\begin{array}{l}\text { 19. SECUAITY CLASSIFICATION } \\
\text { OF ABSTRACT } \\
\text { Unclassified }\end{array}$ & 20. LIMITATION OF ABSTRACT \\
\hline NSN 7540-01-280-5500 & & & $\begin{array}{l}\text { andard Form } 298 \text { (Rev. 2-89) } \\
\text { scribed by ANSI Std. Z39-18 }\end{array}$ \\
\hline
\end{tabular}

